\title{
"You say it's liking, I say it's wanting ...". On the difficulty of disentangling food reward in man
}

Citation for published version (APA):

Havermans, R. C. (2011). "You say it's liking, I say it's wanting ...". On the difficulty of disentangling food reward in man. Appetite, 57(1), 286-294. https://doi.org/10.1016/j.appet.2011.05.310

Document status and date:

Published: 01/01/2011

DOI:

10.1016/j.appet.2011.05.310

Document Version:

Publisher's PDF, also known as Version of record

Document license:

Taverne

Please check the document version of this publication:

- A submitted manuscript is the version of the article upon submission and before peer-review. There can be important differences between the submitted version and the official published version of record.

People interested in the research are advised to contact the author for the final version of the publication, or visit the DOI to the publisher's website.

- The final author version and the galley proof are versions of the publication after peer review.

- The final published version features the final layout of the paper including the volume, issue and page numbers.

Link to publication

\footnotetext{
General rights rights.

- You may freely distribute the URL identifying the publication in the public portal. please follow below link for the End User Agreement:

www.umlib.nl/taverne-license

Take down policy

If you believe that this document breaches copyright please contact us at:

repository@maastrichtuniversity.nl

providing details and we will investigate your claim.
}

Copyright and moral rights for the publications made accessible in the public portal are retained by the authors and/or other copyright owners and it is a condition of accessing publications that users recognise and abide by the legal requirements associated with these

- Users may download and print one copy of any publication from the public portal for the purpose of private study or research.

- You may not further distribute the material or use it for any profit-making activity or commercial gain

If the publication is distributed under the terms of Article $25 \mathrm{fa}$ of the Dutch Copyright Act, indicated by the "Taverne" license above, 


\title{
Research review
}

\section{"You Say it's Liking, I Say it's Wanting ...”. On the difficulty of disentangling food reward in man ${ }^{\text {is }}$}

\author{
Remco C. Havermans \\ Maastricht University, Faculty of Psychology E Neuroscience, PO Box 616, 6200 MD Maastricht, The Netherlands
}

\section{A R T I C L E I N F O}

\section{Article history:}

Received 21 March 2011

Received in revised form 16 May 2011

Accepted 17 May 2011

Available online 23 May 2011

\section{Keywords:}

Appetite

Eating behavior

'Liking'

Reward

'Wanting'

\begin{abstract}
A B S T R A C T
According to the influential theory of Berridge (1996, 2009), food reward comprises two components: food 'liking' and 'wanting', with 'liking' referring to the pleasure derived from eating a given food and 'wanting' referring to appetitive motivation. Animal research shows that these two components have separate neural correlates. In examining reward driven eating in man, researchers have thus begun to develop interest in indicators of 'liking' and 'wanting'. But validating 'liking' and 'wanting' requires the dissociation of these components when theory dictates they should diverge. One such circumstance is neural sensitization as this leads to exaggerated 'wanting' without increased 'liking'. However, there are no data suggesting that such sensitization is the likely result of (over)eating. Without sensitization, one cannot determine whether task performance is indicative of true food 'liking' or 'wanting'. It is concluded that it is important to assess appetite and palatability in the study of reward driven eating, but determining whether these measurements reflect either food 'wanting' or food 'liking' is not.
\end{abstract}

(c) 2011 Elsevier Ltd. All rights reserved.

\section{Contents}

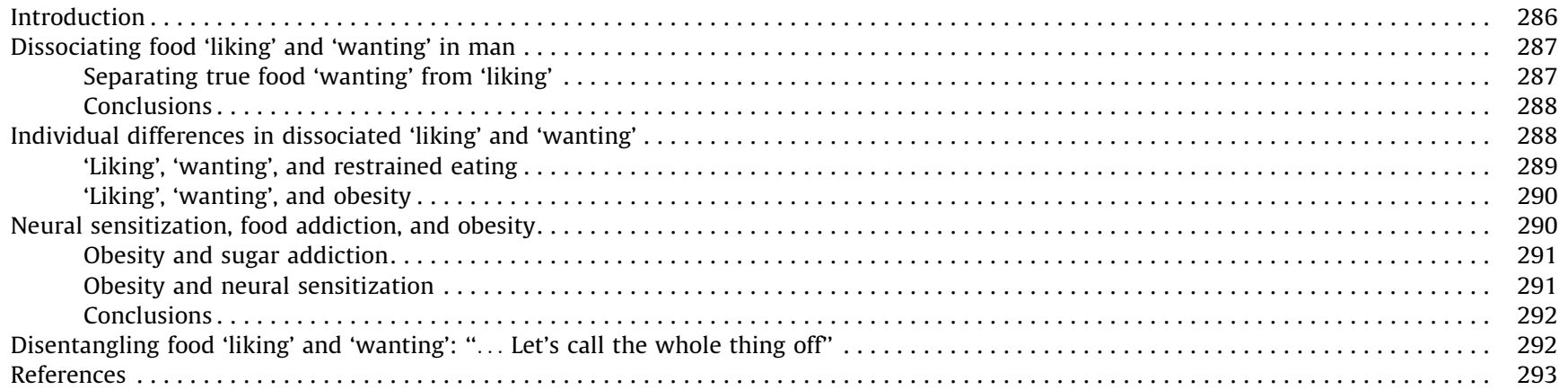

\section{Introduction}

One may argue that in environments where highly palatable foods are abundant and readily available, hunger and satiety do not play an important role in determining eating behavior (i.e., food

\footnotetext{
The author would like to thank Anne Roefs and Chantal Nederkoorn for discussions and for providing detailed comments on an earlier draft. The author would further like to thank the Jansen lab for helpful and much appreciated 'Gedankenflapperflackern'.

E-mail address: r.havermans@maastrichtuniversity.nl.
}

intake and selection). Many scholars agree that in these settings appetite reflects hedonic motives rather than homeostatic needs (see e.g., Appelhans, 2009; Berridge, 2004; Eertmans, Baeyens, \& Van den Bergh, 2001; Finlayson, King, \& Blundell, 2007b; Lowe \& Levine, 2005; Papies, Stroebe, \& Aarts, 2008; Stroebe, Papies, \& Aarts, 2008; Yeomans, Blundell, \& Leshem, 2007). That does not mean that one denies that homeostatic drives influence affective processing of food and food cues (see e.g., Siep et al., 2009; Young, 1959), but in the absence of true physiological needs this influence may be limited. Apart from being a biological necessity, eating can be a source of joy, and particularly high energy dense palatable 
foods are potent rewards. Cuisine is often the central feature of a culture and people derive great pleasure from it as exemplified by the fact that some individuals will spend a lot of money on a carefully prepared meal at a top restaurant (de Castro, Bellisle, \& Dalix, 2000; Rozin, 1996).

It is possible to define eating behavior in terms of need-free hedonic motivation: people eat the foods they like and avoid having to eat foods they do not like (Cabanac, 1992; Eertmans et al., 2001; Lowe \& Butryn, 2007; Young, 1959). This hedonic eating behavior can be characterized as reward driven eating (Appelhans, 2009). What makes studies of food reward or reward driven eating especially relevant is that "hedonic hunger" (Lowe \& Butryn, 2007; Lowe \& Levine, 2005) can override homeostatic signals and hence promotes weight gain. Palatability is an important predictor of food intake, hedonic responses to foods are closely linked to food choice, food palatability induces overconsumption particularly when sated, and the mere exposure to a preferred food stimulates appetite (see e.g., Jansen et al., 2008; Mustonen, Hissa, Huotilainen, Miettinen, \& Tuorila, 2007; Yeomans et al., 2007). Clearly this "power of food" (Lowe \& Butryn, 2007) undermines weight regulation and contributes to an excessive appetite. In line with this view the current rapid global rise in the prevalence of obesity has prompted much needed research investigating the role of food reward in eating.

Berridge (1996, 2007a) argues that when examining the role of food reward in eating behavior one should make the distinction between food 'liking' and food 'wanting', with 'liking' roughly referring to palatability (i.e. the pleasure derived from eating a given food) and 'wanting' to an incentive motivation or disposition to eat. The division between food 'liking' and 'wanting' relies on animal research showing that different neural substrates underlie the expression of affective food (dis)likes and the disposition to eat (i.e. wanting). Food 'wants', incentive salience, or food cravings are induced by exposure to food and food-related cues, and heavily depend on mesocorticolimbic dopamine activity (i.e., dopamine neurotransmission; Berridge, 2007b). Food 'liking', the affective state triggered by tasting palatable foods, is associated with opioid activation in specific limbic forebrain structures, or "hedonic hotspots” (Berridge, 2009; Berridge \& Kringelbach, 2008; Peciña, Smith, \& Berridge, 2006). In animal research, such food 'liking' hotspots have been found within the medial shell of the nucleus accumbens (Peciña \& Berridge, 2005) and the posterior ventral pallidum (Smith \& Berridge, 2005). Mu-opioid receptor stimulation within these specific neural structures by micro-injections of the opioid agonist DAMGO typically increases sweet taste 'liking', whereas lesions to these areas - especially the ventral pallidum may lead to a complete loss of appetite (Berridge, 2007a, 2009). Interestingly, other neurotransmitter systems within these limbic structures (e.g., endocannabinoid system and GABA-ergic neurotransmission) may also affect food 'liking' and this suggests a complex interplay of neurotransmitter systems in determining hedonic responses to food (Berridge, 2007a; Cooper, 2004). Importantly, food 'wanting' can be disconnected from food 'liking'. For example, treating rats with 6-OHDA leaves them dopamine depleted. These rats are aphagic but still display normal affective reactivity to sucrose (liked) and quinine (disliked) (Berridge \& Robinson, 1998). Conversely, a surplus of dopamine in the rodent brain either as the result of a genetic mutation or due to the administration of amphetamine inducing dopamine release causes elevated sweet food 'wanting', but not 'liking' for sweet food rewards (Peciña, Cagniard, Berridge, Aldridge, \& Zhuang, 2003; Tindell, Berridge, Zhang, Peciña, \& Aldridge, 2005).

In sum, food reward comprises both 'liking' and 'wanting', and these two aspects of food reward each have their own, though interrelated, neural correlates. Importantly, this implies that food 'liking' and 'wanting' can be split under certain circumstances and contribute separately and differently to reward driven eating (Berridge, 2009). Finlayson et al. (2007b, p. 989) state that "if core processes of liking and wanting can independently modulate food reward ..., it is important to understand how they can be approached and rendered suitable for the study of ingestive behaviour in humans". In animals, food 'liking' and 'wanting' can be studied separately by imposing specific brain lesions. The difficulty in identifying and dissecting these food reward components in human eating behavior lies in the obvious fact that one cannot rely on lesion studies and this raises the question whether it is possible at all to dissociate 'liking' and 'wanting' in man. In the present article, the contention is that, given current theory and data, it is impossible to validate measures of true food 'liking' and 'wanting' in man implying that one cannot distinguish between pure 'wanting' and 'liking' when examining human reward driven eating, and that hence the parsing of food reward into 'liking' and 'wanting' is unnecessary.

\section{Dissociating food 'liking' and 'wanting' in man}

Inasmuch as reward driven eating in man is determined by dissociable 'liking' and 'wanting', investigating the separate contributions of 'liking' and 'wanting' to the experience of food reward requires that one is able to objectively measure these food reward components. To this end, various food 'liking' and 'wanting' tasks and tests have been developed or adapted, but it has proven to be very difficult to measure true 'wanting' separate from true 'liking'. A selection of studies typifying these difficulties is described below.

\section{Separating true food 'wanting' from 'liking'}

Finlayson, King, and Blundell (2007a) asked their participants to indicate on a linear scale how pleasant it would be to experience a mouthful of a specific food in order to assess food 'liking'. They also employed a forced choice methodology to assess food 'wanting'. With this method, participants repeatedly had to choose between two food items receiving the instruction to select the food s/he would most want to eat. This allows for the calculation of relative preferences, preferences based on 'wanting'.

Finlayson and colleagues measured food 'liking' and 'wanting' before and after consumption of a meal and found that changes in 'liking' and 'wanting' with meal consumption did not always match. When hungry, participants preferred (i.e. 'wanted') high-fat savory foods over low-fat savory foods with no significant differences in 'liking' for these foods. Further, these hungry participants liked high-fat sweet foods better than low-fat sweet foods in the absence of any significant differences in 'wanting' of these foods. The reverse pattern of results was obtained when the participants were sated. When sated, participants wanted low-fat savory foods over high-fat savory foods and liked low-fat sweet foods better. Finlayson, King, and Blundell (2008), however, failed to replicate these results in a later similar study. Changes in food 'liking' with meal consumption were not completely dissociated from changes in 'wanting'. Finlayson and colleagues (p. 125) thus concluded that "... the findings of the present study provide support for the conceptualisation of preference (in terms of a behavioural outcome) as containing ... elements of liking and wanting". In other words, the relative preference test devised by Finlayson et al. (2007b) does not seem to measure purely 'wanting'.

Another approach to measuring food 'wanting' concerns tasks in which the participant has to perform a certain instrumental response to obtain food reinforcement (see also Mela, 2006). Such a task was employed by Epstein, Truesdale, Wojcik, Paluch, and Raynor (2003). In this study, participants had to perform a game in which they worked for points that could be traded for correspond- 
ing amounts of snack food. The participant had to pull a joystick and feedback provided on a computer screen would tell the participant whether s/he had obtained any points. Not every joystick pull was reinforced and throughout the task the response requirement (i.e., the required number of joystick pulls) for snack reinforcement increased until the end of the task, or when the participant decided to stop. Food deprived participants worked longer for snack food. In other words, the food deprived participants were more motivated to work for a favorite snack food (e.g., chocolate bars or chips). But the food deprivation did not significantly influence 'liking' for chocolate milk, lemon juice, and water. Epstein and colleagues interpreted this finding as a dissociation between hedonic preferences and the reinforcing value of food suggesting a disconnect between 'liking' and 'wanting'. This apparent dissociation, however, is the more likely result of the fact that 'liking' was determined for various drinks and 'wanting' was assessed for a favorite snack food. Of course, to dissociate 'liking' and 'wanting' one has to measure the effects of a manipulation on purported 'liking' and 'wanting' for one and the same food. For example, Havermans, Janssen, Giesen, Roefs, and Jansen (2009) used a similar progressive ratio task in a study assessing whether food 'liking' and food 'wanting' dissociate with sensory-specific satiation. Participants evaluated chips and chocolate milk and then were given several servings of the chocolate milk. As expected, this induced sensory-specific satiation for the chocolate milk, a decrease in liking for the chocolate milk relative to the evaluation of the crisps. Next, half of the participants had to work for chocolate milk, that is, the participant had to press a specific response key for which s/he could receive points representing a certain amount of chocolate milk. The response requirement for points increased exponentially throughout the task. The other half of the participants worked for the chips in the same progressive ratio task. This latter group of participants was found to press the response key for points more often. Hedonic ratings and the motivation for the chocolate milk as measured with the progressive ratio task correlated significantly.

Recently, Lemmens et al. (2009) validated their operationalisation of 'liking' and 'wanting'. Apart from simply asking the participants how much they liked and wanted a given food item, they used computer tasks to separately assess food 'liking' and food 'wanting'. To measure 'liking' participants were presented with all possible combinations of pictures from five different food categories and a non-food category, and they were asked to indicate rapidly, which one of the two presented items they liked the most. This rendered a relative 'liking' score for the 6 categories. 'Wanting' of each category was assessed by measuring the performance on a memory task. The memory task comprised of finding matching pairs of food pictures in a $5 \times 5$ grid. A maximum of 12 pairs could be found. The better the performance on this game, the more different items from the category were offered to the participant to choose from. The participant was always offered the option to choose 0,1 , or 2 pieces of each item of the previously found pairs of food items in the memory game. The outcome variable, or the 'wanting' score, was the total number of selected items per category (ranging between 0 and 24). Participants completed these two tasks and then received a fixed amount of chocolate mousse or cottage cheese to eat. This was done to be able to determine whether the 'liking' and 'wanting' tasks would be sensitive enough in detecting changes in palatability and appetite expected with the consumption of these foods. Therefore, the participants had to perform the 'liking' and 'wanting' tasks again after consuming the chocolate or cheese. All participants had to do this twice in separate sessions, once for the chocolate mousse and once for the cottage cheese. Lemmens et al. found that consumption of the highly liked chocolate mousse led to a much more distinct and elaborate decrease in food 'wanting' than did the consumption of the cottage cheese. Only relative 'liking' for the food category "bread" decreased with the consumption of the chocolate mousse.

Lemmens et al. (2009) conclude that their results show that the computer tasks they developed to measure food 'wanting' and 'liking' are valid. They base this conclusion in large part on the reproducibility of the 'wanting' and 'liking' scores across the two test sessions. The concordance between the two measurements was approximately $70 \%$. Of course, this percentage shows that the tasks allow for adequately reliable measurements, but Lemmens and colleagues are mistaken when they argue that this reproducibility also implies validity of the 'liking' and 'wanting' computer tasks. Moreover, performance on their 'wanting' task depends on memory and not just appetitive motivation and thus may not be suitable to measure individual differences in 'wanting' as memory capacity also differs between individuals. Note further that their relative liking task is very similar to the relative food preference methodology developed by Finlayson et al. (2007a) thought to primarily assess food 'wanting'. The only real difference between these two tasks seems to be the explicit a priori instruction to express preference on the basis of either one's wanting (Finlayson et al.) or one's liking (Lemmens et al.) of the presented food.

\section{Conclusions}

Several researchers have taken interest in measuring and differentiating between food 'liking' and food 'wanting' in man, but as of yet, it has proven to be very difficult to distinguish this 'liking' and 'wanting'. Of course, that it is difficult does not imply that it is impossible.

It is important to note that the studies described above often lacked a clear hypothesis. Several researchers, however, seem to expect that the slightest nudge will have food 'liking' and 'wanting' running out of sync. The somewhat implicit hypothesis then often appears to be that simply eating a food, or being food deprived for a limited amount of time, suffices in revealing the presupposed loose coupling between food 'liking' and 'wanting'. Not only does this go against the phenomenology of appetite, it also lacks corroboration from theory and data. Food 'liking' and 'wanting' are highly entangled. Indeed, as Berridge (1996) already noted, when considering basic animal research it is clear that most eating manipulations (e.g., caloric hunger and satiety, sensory-specific satiation, and conditioned flavor preferences and aversions) are characterized by conjunct changes in food 'liking' and 'wanting'. In other words, when it comes to "normal" reward driven eating, food 'liking' and 'wanting' typically co-vary. This implies that it is impossible to validate presumed measures of 'liking' and 'wanting' when considering such normal eating behavior.

Berridge (2009) recently speculated that eating disorders may reflect a disconnect between food 'liking' and 'wanting', a disconnect that might promote abnormal eating behaviors such as eating binges. When true, food reward does have separate functional aspects that are meaningful, at least with regard to abnormal eating. This also means that one can validate measures of 'liking' and 'wanting' in those individuals that one would expect to demonstrate a disconnect between 'liking' and 'wanting'.

\section{Individual differences in dissociated 'liking' and 'wanting'}

Food 'liking' and 'wanting' do not likely diverge with normal reward driven eating, but it may in the case of abnormal eating behavior. In fact, a disconnect between 'liking' and 'wanting' might be at the heart of aberrant dietary habits, such as binge eating in case of different eating disorders or regular caloric overconsumption associated with weight gain (Berridge, 2009; Yeomans et al., 2007). It has been suggested that the relative overconsumption of 
high energy dense palatable foods observed in obese individuals is the result of excessive food 'wanting', not of elevated 'liking' (Mela, 2006). But how would this latter divergence come about?

Robinson and Berridge (1993, 2000, 2003) attribute the compulsive nature of addictive behaviors to incentive sensitization, arguing that the compulsion to use a certain drug or alcohol is best explained in terms of an excessive appetite for drugs or alcohol. According to Robinson and Berridge, repeated drug or alcohol use may lead to neural sensitization increasing one's sensitivity to drug or alcohol reward. Through Pavlovian conditioning such neural sensitization then comes to promote excessive incentive salience attribution to drugs or alcohol related cues, a process termed incentive sensitization. Due to the incentive sensitization, drug or alcohol cues become extra desirable, capable of eliciting strong craving or 'wanting'. Furthermore, one is thought to develop an attention bias for these drug or alcohol related stimuli (Franken, 2003). If such disproportionate incentive salience attribution is also possible with the consumption of palatable high calorie foods, one would expect that the motivational appeal (or 'wanting') of these energy dense foods is particularly strong in individuals with a propensity for weight gain and/or experienced difficulty with weight regulation.

\section{'Liking', 'wanting', and restrained eating}

Restrained eaters are concerned about their body weight and shape and hence try to restrict their food intake. Restrained eating, however, is typically coupled with a higher body weight and associated with long term weight gain. Clearly, restrained eaters are not particularly successful at regulating their weight, and could thus be described as unsuccessful (or chronic) dieters (Heatherton, Herman, Polivy, King, \& McGree, 1988). Indeed, research has shown that restrained eaters, unlike unrestrained eaters, are cajoled into overeating by a variety of manipulations (see e.g., Herman \& Mack, 1975; Jansen \& Van den Hout, 1991; Schotte, Cools, \& McNally, 1990).

Giesen, Havermans, Nederkoorn, Strafaci, and Jansen (2009) hypothesized that restrained eaters invest more effort in obtaining snack food than unrestrained eaters. More specifically, it was investigated whether the relative reinforcing value of snack food differs between restrained (but non-dieting) eaters and unrestrained eaters. The relative reinforcing value of snack food was assessed by means of a concurrent schedules task that measures how hard a participant works for his/her most liked snack food, compared to a most liked low-caloric food as established in a prior taste test. Participants were offered the choice between working for points for high calorie snacks or low calorie foods. At the start of the task the response requirement for both foods was still equal. However, as the task progressed the response requirement for earning snack points increased, whereas the response requirement for the low-caloric food points remained the same. Hedonic ratings for the two food options (high energy dense versus low energy dense) did not differ, not within participants, and not between the restrained and unrestrained eaters, but the number of responses for the high calorie snack food was significantly higher for the restrained eaters (see also Giesen, Havermans, \& Jansen, 2010). This pattern of results can be explained in terms of restrained eaters showing exaggerated snack 'wanting' in the absence of any exaggerated snack 'liking'. However, one may doubt the validity of subjective ratings of 'liking' as they suffer from self-presentation especially in those individuals who would feel embarrassed and self-conscious about admitting that one likes chocolate chip cookies better than cucumber or grapes. Hedonic ratings of food clearly are not ideal for measuring food 'liking' in restrained eaters but how then should one measure it?

In animal studies, researchers rely on observing the number of specific responses that reflect experienced affective value, such as frequency of tongue protrusions for food likes and gapes for dislikes in rodents in so called taste reactivity tests (Berridge, 2000). Similar behavioral responses to sweet liked taste and disliked bitter tastes were found in nonhuman primates (Steiner, Glaser, Hawilo, \& Berridge, 2001) and human infants (Ganchrow, Steiner, \& Daher, 1983; Steiner, 1974; Steiner et al., 2001). It should be noted though that in humans at least there seems to be an asymmetry in affective taste reactivity. For example, Rosenstein and Oster (1988) exposed 12 2-h old newborns to a salty, sour, bitter and sweet taste, and recorded their facial expressions to these exposures. Using the Facial Action Coding System (henceforth FACS), the researchers were able to discriminate between facial expressions for sour, salty, bitter, and sweet taste. They note however, that there were fairly large individual differences suggesting that orofacial responses to tastes may be far less stereotypical than assumed previously by Steiner (1974). Untrained observers were only able to recognize gaping as a clear sign of dislike. This suggests that it is relatively easy to observe variations in expressed dislike or disgust, but not variations in facial expressions of food liking (see also Forestell \& Mennella, 2007; Soussignan, Schaal, Marlier, \& Jiang, 1997). One might speculate that neonates are perhaps less expressive than infants at an older age, thus troubling the observation of variations of more subtle liking responses to foods in newborns. However, employing FACS, Zeinstra, Koelen, Colindres, Kok, \& de Graaf (2009) also experienced difficulties trying to find indicators capable of discriminating food likes in 5-13 year old children. They too concluded that "... facial expressions are suitable to measure dislike, but not suitable to measure various gradients of food acceptance ..." (p. 623) (see Booth, Higgs, Schneider, \& Klinkenberg, 2010, for a similar finding and conclusion).

Finlayson et al. (2008, p. 126) argued that "The explicit measurement of liking and wanting are subject to crosscontamination, however this confound can be circumvented by measuring one - and ideally both - processes implicitly." This is exactly what Veenstra and de Jong (2010) recently set out to do. They obtained an implicit measure of liking for foods: an Affective Simon Task (AST). This task is an RT task in which participants were shown pictures in either landscape or portrait size and they were instructed to say "tasty" in case of landscape pictures and "untasty" in case of portrait sized pictures. The pictures themselves could represent high-fat or low-fat foods. The underlying logic of the task is that if one likes the taste of the picture shown and the orientation picture requires one to say "tasty" (congruent trial) one is much faster than if one is required to say "untasty" (incongruent trial). With this task Veenstra and de Jong found that both unrestrained and restrained eaters show implicit liking for high-fat foods relative to low-fat foods.

Veenstra and de Jong (2010) used a different AST to assess automatic approach tendencies towards food. In this task, participants were required to let a manikin presented on a computer screen approach pictures of objects viewed from the top and avoid pictures of objects viewed from the side. The objects depicted were high-fat foods, low-fat foods, and neutral non-food objects. Veenstra and de Jong argue that if one craves or 'wants' high-fat foods, one would be faster at approaching these pictures than if one is instructed to avoid these. What Veenstra and de Jong found with this task is that the restrained eaters show stronger food approach tendencies (regardless of fat content) relative to the unrestrained eaters. Veenstra and de Jong argue that the latter automatic approach tendencies refer to incentive salience or 'wanting' of the food pictures and not the affective valence of the pictures. That may be true, but the overall pattern of findings is not what one would expect if one hypothesizes that overeating in restrained eaters is the likely result of incentive sensitization. One would only then expect a dissociation between 'liking' and 
'wanting' for foods in the restrained eaters, not the unrestrained eaters. Furthermore, one would expect to see strong 'wanting' (without strong 'liking') of particularly high energy dense foods in case of incentive sensitization. Again, this is not what was found. Indeed, the restrained eaters displayed an approach tendency towards both high and low calorie foods. This latter approach tendency could just as well be interpreted as reflecting the automatic activation of a dieting goal (see e.g., Havermans, Giesen, Houben, \& Jansen, 2011; Stroebe et al., 2008), rather than the automatic 'wanting' or desire for low energy dense foods. Naturally, such a dieting goal would be apparent in restrained eaters and not so much in unrestrained eaters. Furthermore, as Veenstra and de Jong acknowledge, the AST manikin task is generally thought to assess valence (i.e., likes and dislikes), not exclusively motivation for given stimulus categories (see also Krieglmeyer, Deutsch, De Houwer, \& De Raedt, 2010).

In sum, restrained eaters and unrestrained eaters do differ in their eating behavior and their motivation towards high calorie palatable foods, but whether this individual difference is the result of incentive sensitization is questionable. A more likely role for incentive sensitization seems to concern obesity.

\section{'Liking', 'wanting', and obesity}

The incidence of obesity, defined as severe overweight due to an unhealthy amount of body fat (Jeffery et al., 2000), is increasing worldwide. It is the result of a positive energy balance; more energy is consumed than is expended (Jéquier, 2002). A positive energy balance causes weight gain and it is especially the overconsumption of high energy dense foods that contributes to this positive energy balance (Swinburn, Sacks, \& Lo, 2009; Westerterp \& Speakman, 2008). But what causes one to overeat these foods? Could this be the result of incentive sensitization?

Despite some reservations by Finlayson et al. (2008) concerning their explicit food preference task measuring 'wanting' uncontaminated by food 'liking', Ouwehand and Papies (2010) used this method of relative preference to assess food 'wanting' in normal weight and overweight restrained eaters after unobtrusive exposure to attractive food cues. Such exposure was found to increase 'wanting' for high calorie foods in the overweight restrained eaters, whereas it decreased presumed 'wanting' for the normal weight restrained eaters. Unfortunately, Ouwehand and Papies did not assess food 'liking' and hence it is possible that food 'liking' contributed to the expressed preference for high calorie foods in the overweight restrained eaters after being primed with palatable high energy dense foods.

Ouwehand and de Ridder (2008) used a questionnaire version of the relative reinforcing value task (Goldfield \& Epstein, 2002) to assess whether food temptations differentially affect food 'wanting' and subjectively rated food 'liking' in normal-weight and overweight women. Food 'wanting' decreased when exposed to food temptations, though only in the normal weight women. Temptation did not seem to affect food 'liking' and subjective hedonic ratings did not correlate with the 'wanting' measure. However, for the 'wanting' measure the participants had to indicate for a total of 16 foods how much effort (i.e., instrumental responses) one would be willing to invest to obtain each food. These were foods that the participant typically liked. The researchers did not use the liking scores for these 16 foods as the food 'liking' outcome. Instead, food 'liking' was assessed by measuring how much the participants on average liked three different sugar solutions. But such general liking for sweet taste has very little to do with the motivation to eat specific idiosyncratically preferred foods and as the liking scores were averaged across the three different solutions one cannot rule out the possibility that food temptations did lead to a shift in hedonic responses; that is, a change from liking the sweetest solution best to liking the unsweetened solution best, or vice versa. Nonetheless, Ouwehand and de Ridder concluded that food temptations selectively decrease 'wanting' predominantly in normal weight women, because they try to adhere to a strong weight maintenance goal. Certainly, many factors ultimately determine food choice. The desire to regulate weight is such a factor, but Berridge has repeatedly stated that such more cognitive considerations contributing to food choice and food intake does not represent 'wanting'. Incentive salience food 'wants' are elicited directly by exposure to food reward cues and do not require understanding of the consequences of procuring and ingesting a 'wanted' food. In that sense, 'wanting' is a core appetitive motivation (see e.g., Berridge, 2004) and it is questionable whether Ouwehand and de Ridder were able to tap that motivation.

When comparing overweight/obese participants with normalweight participants, Giesen, Havermans, Douven, Tekelenburg, and Jansen (2010) also found that the overweight/obese participants worked harder to obtain snack foods despite the fact that they subjectively liked these foods to an equal degree relative to the normal-weight controls. But as was the probable case for restrained eaters, this dissociation may simply denote the unreliability of subjective ratings due to self-presentation and thus cannot be considered as definite proof of a disconnect between food 'liking' and food 'wanting' within the obese. A stronger case for incentive sensitization contributing to obesity could be made if one could demonstrate neural sensitization of the dopamine reward circuitry as such neural sensitization is requisite for incentive sensitization (Berridge, 2009).

\section{Neural sensitization, food addiction, and obesity}

With repeated drug use certain structures within the brain become more tolerant to the effects of the drug, but other parts or networks become sensitized, especially the reward related structures such as the nucleus accumbens and the ventral tegmental area. One can assess such neural sensitization with behavioral studies. The structures that tend to sensitize with drug use are partly involved in the regulation of overall behavioral activity or psychomotor arousal. Behavioral activity increases in response to drug use and this psychomotor arousal grows stronger with neural sensitization. In animals, this psychomotor arousal as the result of neural sensitization is expressed as fast repetitive stereotypical behaviors (Robinson \& Berridge, 1993, 2000, 2003). Similar psychomotor sensitization has been demonstrated in humans. In humans, the administration of amphetamine increases the frequency of eye blinks. This is a psychomotor effect that at first is very subtle but sensitizes with repeated amphetamine administrations, indicative of neural sensitization (Strakowski \& Sax, 1998).

Does neural sensitization also affect reward driven eating? Some studies indeed suggest that this is the case. For example, Wyvell and Berridge (2001) demonstrated in rats that with repeated microinjections of amphetamines in the nucleus accumbens these rats came to work harder for a sweet sucrose reward, particularly in the presence of Pavlovian cues signaling this reward. Neural sensitization as the result of repeated drug administration may thus induce cross sensitization to food 'wanting'. Here, of course, the neural sensitization was established through drug administration but animal studies suggest that consumption of palatable high energy dense foods can also lead to neural sensitization. For example, with a diet of daily intermittent sucrose access, rats became hyperactive in response to a low dose of amphetamine, a dosage that normally would not induce any psychomotor arousal (Avena \& Hoebel, 2003). Further, rats subsequently forced to abstain from a daily intermittent sucrose diet, drank more alcohol (Avena, Carrillo, Needham, Leibowitz, \& 
Hoebel, 2004), and self-administered more cocaine (Gosnell, 2005). These studies suggest that with intermittent opportunity for sucrose consumption the dopaminergic reward system becomes sensitized in much the same way that drugs of abuse have been shown to induce neural sensitization. Does such sensitization play a role in overconsumption and thus the development of obesity?

\section{Obesity and sugar addiction}

In rats it seems that sugar intake under specific conditions can lead to neural sensitization of the mesocorticolimbic dopamine circuitry. If so, then these animals should also show signs of what could be called a sugar addiction. Avena, Rada, and Hoebel (2008) argue that this is indeed the case. More specifically, a month of daily intermittent feeding of rats - with $12 \mathrm{~h}$ food deprivation and $12 \mathrm{~h}$ access to a diet of a sugar solution and lab chow - has been found to lead to (1) the animals showing sugar bingeing (Colantuoni et al., 2001), (2) opiate-like withdrawal indicated by behavioral signs of anxiety and depression (Colantuoni et al., 2002), and (3) craving, that is, enhanced responding for sugar (Avena, Long, \& Hoebel, 2005). One might argue that this sugar addiction might also play a role in the current rise in the incidence of obesity.

Sugar forms an important source of energy and thus its overconsumption would precipitate weight gain. Indeed, epidemiological research shows that the increasing prevalence of obesity in the past few decades parallels increased sugar consumption (Drewnowski, 2007). But Drewnowski is correct in pointing out that these time trends do not imply a direct association between obesity and sugar intake. He further notes that younger males are the highest consumers of sugar (in whatever form), "who are both thinner and more active than older persons, whose sugar consumption is low" (Drewnowski, p. 165). Moreover, the consumption of sugar sweetened beverages and liquids have been found to contribute to both weight gain and weight maintenance/ loss depending on their costs with cheaper drinks contributing to weight gain and expensive drinks being associated with weight loss (see also Ledikwe et al., 2007). This led Drewnowski to suggest that it is not the consumption of a specific macronutrient such as fats or carbohydrates (e.g., sugars) that has led to the current obesity epidemic. In the past few decades an increasing amount and variety of high fat and high sugar food products have been introduced to the consumers. Low cost palatable high energy dense foods provide cheap calories, which (regardless of whether these calories are from fat, protein, carbohydrates, or alcohol) are associated with weight gain.

As for sugar addiction, sugar addicted rats generally do not seem to suffer from excessive weight gain (Avena, 2010; Colantuoni et al., 2002). They binge on sugar but compensate for this excess intake by eating less lab chow. Nevertheless, one can maintain that sugar addiction - if not a definite causal mechanism - can still be a risk factor for the development of severe overweight, but this too is unlikely. Rats do not develop a sugar addiction when on a month-long intermittent feeding diet of sugar and fat, and they do not develop sugar binges when they have ad libitum access to sugar. Sugar addiction in rats only seems to develop with the intermittent feeding schedule of sugar and lab chow (Avena et al., 2008). People do not consume their sugars in this very specific pattern and thus it is unlikely that sugar addiction as shown in laboratory rats would ever develop in free-living individuals (Benton, 2010). Further, experiences of food cravings are anything but an anomaly in humans and these cravings rarely (if ever) involve pure macronutrients such as sugar. Individuals crave palatable foods typically rich in both sugars and fats, such as chocolate, or cake, or chocolate cake (Drewnowski \& Bellisle, 2007). Even though such food cravings have been found to be associated with changes in the fMRI BOLD signal in brain areas also implicated in the experience of craving for drugs of abuse, this merely shows the evolutionary underpinnings of drug cravings (Benton, 2010; Pelchat, Johnson, Chan, Valdez, \& Ragland, 2004).

Although it is unlikely that the current obesity epidemic is the result of a specific sugar addiction, and that food cravings as such cannot be taken as a clear indication that food is addictive, this does not discount the theoretical possibility for considerable weight gain being associated with a more general food addiction; that is, a dependence upon high energy dense palatable foods that like drugs of abuse are capable of potent stimulation and adaptation of brain reward systems (Avena, 2010). If so, one would still expect obesity to be associated with some degree of neural sensitization of the mesolimbic dopaminergic reward system (Berridge, 2009). Individuals who might develop neural sensitization with repeat consumption of palatable foods and drinks would come to experience exaggerated food 'wanting' that is no longer in step with their food 'liking', hence promoting caloric overconsumption and precipitating weight gain.

\section{Obesity and neural sensitization}

Mela (2006) suggested that as obese individuals rarely report an increased liking or hedonic preference for high calorie foods relative to normal-weight persons, components of food reward other than 'liking' must be considered as the more important driver for overeating. In line with the distinction between food 'liking' and 'wanting', Mela argued that incentive sensitization might explain caloric overconsumption (p. 15): "Considerable attention has been given to the perception of orosensory stimuli and explicit liking of foods, yet variation in obesity is not clearly related to variation in the hedonic experience or explicit pleasure of eating". If so, one would expect that in obese individuals food cues elicit stronger reactions in dopamine related circuits (e.g., the striatum) as hyperreactivity within this circuitry has been found to be associated with higher food 'wanting' (Berridge, 2009).

Is there any evidence for neural sensitization in the obese? That does not seem to be the case. In a PET study, Wang et al. (2001) examined striatal dopamine D2 receptor availability in obese individuals and compared this with D2 receptor availability among normal-weight controls, and found that this availability was lower for the obese participants. Wang and colleagues speculated that this may represent down-regulation of receptor sites to compensate for overstimulation of these receptors. Moreover, this down-regulation might then serve to perpetuate overeating, as more food would have to be eaten to experience the same degree of food reward as before. Volkow et al. (2008) found a similar pattern of results and also found indications that in obese individuals the low availability of striatal D2 receptors was correlated with prefrontal metabolism; that is metabolism in the prefrontal region was lower with smaller availability of these particular dopamine receptors. As the prefrontal lobe is associated with inhibitory control, Volkow and colleagues postulated that dopaminergic modulation of the prefrontal region is disturbed in obese individuals, thus undermining self-regulation.

Berridge (2007a, 2009) finds the dopamine receptor downregulation account for overeating and obesity problematic as it (1) partly seems to depend on the obsolete notion that dopamine is responsible for the experience of pleasure and that (2) it appears to require that the less pleasure one derives from a given food the more one will eat it. Generally, if one comes to like a food less, due to aversion learning or sensory specific satiation, one will be inclined to eat less of that food, not more of it. Notwithstanding this criticism, Stice, Spoor, Bohon, \& Small (2008) found that individuals with reduced dopamine $\mathrm{D} 2$ receptor availability due to a polymorphism in the DRD2 gene (i.e., an A1 allele of the TaqIA SNP, the so termed TaqIA A1 genotype) showed a relatively blunted 
striatal BOLD response when asked to imagine consuming a palatable food. Notably, these individuals were at greater risk for weight gain at a 1-year follow-up. This suggests that dopamine hypo-responsiveness promotes weight gain. However, in a later study, Stice, Yokum, Bohon, Marti, \& Smolen (2010) found that women showing weight gain also showed a reduction in striatal responsivity to palatable food consumption. Stice and colleagues therefore suggested that low sensitivity of the reward circuitry puts one at risk for weight gain and that the following reduction in sensitivity of the reward circuitry acts as feed forward mechanism promoting further overeating and weight gain.

Stice, Yokum, Blum, \& Bohon (2010) recently replicated their earlier findings, but also found an increased risk for weight gain among participants without the A1 allele and an increased striatal response with imagined intake of palatable foods. This suggests that both hypo- and hyper-responsivity of dopamine reward circuitry may add to weight gain. How can this be? Is it perhaps the case that neural sensitization in reward related brain areas such as the striatum can and does happen in man, but only when one does not have a TaqIA A1 allele? That is a possibility, but it is important to note that the larger striatal BOLD response in these individuals plus their increased risk of weight gain does not necessarily reflect incentive sensitization. It may very well be a sign of a strong hedonic preference for palatable high-calorie foods as the striatum also includes the opioid hedonic hotspots (Peciña et al., 2006). Interestingly, opioid agonists have been found to increase the intake of preferred foods (Gosnell and Levine, 2009). Conversely, opioid antagonists tend to decrease intake of especially palatable foods (Kelley et al., 2002; Levine \& Billington, 2004; Yeomans \& Gray, 2002). One might therefore speculate that obesity is associated with sensitized opioid (not dopamine) brain circuitry.

\section{Conclusions}

Overall, human research results suggest that obesity is associated with a blunted dopamine response and not the hypothesized sensitized response to food cues. These results could be interpreted as a decrease in brain dopamine promoting food intake, which is diametrically opposite to the animal findings (see Berridge, 2007a). However, one might still argue that decreased dopamine D2 receptor availability does not necessarily negate neural sensitization as such sensitization might still be expressed as elevated dopamine release (Berridge, 2007a). If one would still maintain that in humans decreased dopamine activity and availability promotes food intake, then the increase of brain dopamine should inhibit eating. This latter anorectic effect of dopamine has indeed been demonstrated in a small sample of obese males by Leddy et al. (2004). They had their participants ingest a placebo, or a moderate dose of methylphenidate, or a high dose of methylphenidate in a within-subject double blind study. Methylphenidate is a dopamine reuptake inhibitor and thus increases brain dopamine. Next, the participants were given the instruction to eat as much as they would like from a pizza. Overall, energy intake starkly decreased with methylphenidate; $23 \%$ less calories were consumed with the moderate dose of methylphenidate, and $34 \%$ less energy was consumed in case of the high dose. These results too render it unlikely that neural sensitization of the dopamine reward system contributes to obesity. It should be noted though that the anorexic effect of methylphenidate may be attributed to selective increase of extracellular dopamine in regions other than mesolimbic reward circuitry.

\section{Disentangling food 'liking' and 'wanting': “... Let's call the whole thing off"}

According to Berridge (1996, 2009), there is cumulating evidence that separate neural structures and neurotransmitter systems are involved in the respective processing of incentive salience and food hedonics. One may doubt whether such a conclusion is warranted given the data, but that is a discussion outside the scope of the present article. The primary aim of this paper was to critically evaluate the recent attempts to measure the contributions of assumed separable food 'wanting' and 'liking' in man. Though separable, the neural correlates of this food 'wanting' and 'liking' are not some loosely coupled systems, they are highly interconnected. What that means is that ordinarily any manipulation affecting 'wanting' is bound to affect food 'liking' in a similar way (Berridge, 1996; Havermans et al., 2009). An increase in 'liking' for, say, chocolate is paired with elevated chocolate 'wanting', and a decrease in chocolate 'wanting' would be matched by reduced 'liking'.

With lesion studies one can study the separate contribution of 'wanting' and 'liking' to food intake and food choice. These studies are important as they show the neural correlates of food reward processing and reward driven feeding, but have also shown that food 'liking' does not cause food 'wanting' (or vice versa). Nonetheless, 'liking' and 'wanting' are not like two sides of the same food reward coin. Rather, they are like two halves of one side of that coin. One can observe and study 'liking' and 'wanting' separately, but this requires cutting the coin in half.

Apart from specific brain lesions, animal studies show that repeated administration of drugs of abuse can lead to a marked disconnect between drug 'wanting' and 'liking' with incentive sensitization expressed as strong 'wanting' without necessarily strong 'liking' (Robinson \& Berridge, 2003). This incentive sensitization is thought to be a potential model for human addictive behavior. But one should note that apart from a few studies demonstrating an association between increased extracellular dopamine release in the ventral striatum and self reported drug wanting (Leyton et al., 2002) or drug use in patients with Parkinson's disease (Evans et al., 2006), this is still a largely untested hypothesis. The empirical evidence for human drug or alcohol dependence being associated with (or even the result of) incentive sensitization is scarce and equivocal (Hobbs, Remington, \& Glautier, 2005; Ostafin, Marlatt, \& Troop-Gordon, 2010; Willner, James, \& Morgan, 2005). Furthermore, the validity of purported implicit measures of drug 'wanting' and 'liking' was found to be questionable in a recent study among smokers (Tibboel et al., 2011). Even so, one might still argue that aberrant eating behavior is the result of incentive sensitization and this is exactly what has been proposed as the central mechanism underlying overeating and excessive weight gain (see e.g. Mela, 2006). However, such incentive sensitization should be associated with underlying neural sensitization of the dopaminergic reward systems. Such neural sensitization indeed seems to increase food 'wanting' as demonstrated in animals, but in humans there is no definitive evidence or even a clear indication for neural sensitization as the result of food intake. The lack of empirical evidence for neural and corresponding incentive sensitization obviates the speculation that food 'wanting' and not 'liking' is the primary driver for overeating.

In the absence of sensitization the two components of food reward are unlikely to diverge in their contribution to food reward and this makes it impossible to validate operational definitions of food 'liking' and food 'wanting'. Note that this also means that even if 'liking' and 'wanting' contribute to typical eating behaviors in different degrees, one cannot determine this conclusively with any measure available now or in the future. What to do then with all these different behavioral tasks and tests of which it has been claimed that they measure either 'liking' or true 'wanting'? Again, in the absence of data suggesting that in certain cases food 'liking' and food 'wanting' dissociate, any debate of whether a given task measures 'liking' or 'wanting' is as much premature as it is 
unnecessary. Nevertheless, this does not render the aforementioned tasks redundant. They still provide valuable information on what one might consider reward driven eating. Fruitless debates on whether this or that task is measuring true food 'wanting', or 'liking', or a bit of both can be avoided by reporting precisely that what one knows and everyone agrees on the task or test is measuring. In case of a progressive ratio of food reinforcement task, one measures motivation or the effort one is prepared to invest in obtaining a given food (Epstein et al., 2003). A related concurrent schedules task can provide insight into the relative reinforcing value of a particular food (Saelens \& Epstein, 1996). With the food choice tasks developed by Finlayson et al. (2007a), and Lemmens et al. (2009) one is able to assess relative food preferences. All the tasks and tests mentioned in the present article can be said to measure certain aspects of food reward. Naturally, what specific empirical indicators of food reward are ultimately used in any study concerning reward driven eating should depend on the context of the research question, but whether these tasks are capable of assessing a separate contribution of 'liking' or 'wanting' should no longer trouble the researcher.

\section{References}

Appelhans, B. M. (2009). Neurobehavioral inhibition of reward-driven feeding. Implications for dieting and obesity. Obesity, 17, 640-647.

Avena, N. M. (2010). The study of food addiction using animal models of binge eating. Appetite, 55, 734-737.

Avena, N. M., Carrillo, C. A., Needham, L., Leibowitz, S. F., \& Hoebel, B. G. (2004). Sugardependent rats show enhanced intake of unsweetened ethanol. Alcohol, 34, 203 209.

Avena, N. M., \& Hoebel, B. G. (2003). A diet promoting sugar dependency causes behavioral cross-sensitization to a low dose of amphetamine. Neuroscience, 122, 17-20.

Avena, N. M., Long, K. A., \& Hoebel, B. G. (2005). Sugar-dependent rats show enhanced responding for sugar after abstinence. Evidence of a sugar deprivation effect. Physiology \& Behavior, 84, 359-362.

Avena, N. M., Rada, P., \& Hoebel, B. G. (2008). Evidence for sugar addiction. Behaviora and neurochemical effects of intermittent, excessive sugar intake. Neuroscience and Biobehavioral Reviews, 32, 20-39.

Benton, D. (2010). The plausibility of sugar addiction and its role in obesity and eating disorders. Clinical Nutrition, 29, 288-303.

Berridge, K. C. (1996). Food reward. Brain substrates of wanting and liking. Neuroscience and Biobehavioral Reviews, 20, 1-25.

Berridge, K. C. (2000). Measuring hedonic impact in animals and infants. Microstructure of affective taste reactivity patterns. Neuroscience and Biobehavioral Reviews, 24, 173-198.

Berridge, K. C. (2004). Motivation concepts in behavioral neuroscience. Physiology $\mathcal{E}$ Behavior, 81, 179-209.

Berridge, K. C. (2007a). Brain reward systems for food incentives and hedonics in normal appetite and eating disorders. In T. C. Kirkham \& S. J. Cooper (Eds.), Progress in brain research: Appetite and body weight (pp. 191-216). Academic Press.

Berridge, K. C. (2007b). The debate over dopamine's role in reward. The case for incentive salience. Psychopharmacology, 191, 391-431.

Berridge, K. C. (2009). 'Liking' and 'wanting' food rewards. Brain substrates and roles in eating disorders. Physiology \&' Behavior, 97, 537-550.

Berridge, K. C., \& Kringelbach, M. L. (2008). Affective neuroscience of pleasure. Reward in humans and animals. Psychopharmacology, 199, 457-480.

Berridge, K. C., \& Robinson, T. E. (1998). What is the role of dopamine in reward. Hedonic impact, reward learning, or incentive salience? Brain Research Reviews, 28 309-369.

Booth, D. A., Higgs, S., Schneider, J., \& Klinkenberg, I. (2010). Learned liking versus inborn delight. Can sweetness give sensual pleasure or is it just motivating? Psychological Science, 21, 1656-1663.

Cabanac, M. (1992). Pleasure. The common currency. Journal of Theoretical Biology, 155 $173-200$.

Colantuoni, C., Rada, P., McCarthy, J., Patten, C., Avena, N. M., Chadeayne, A., et al. (2002). Evidence that intermittent, excessive sugar intake causes endogenous opioid dependence. Obesity Research, 10, 478-488.

Colantuoni, C., Schwenker, J., McCarthy, J., Rada, P., Ladenheim, B., Cadet, J. L., et al (2001). Excessive sugar intake alters binding to dopamine and mu-opioid receptors in the brain. Neuroreport, $12,3549-3552$.

Cooper, S. J. (2004). Endocannabinoids and food consumption. Comparisons with benzodiazepine and opioid palatability-dependent appetite. European Journal of Pharmacology, 500, 37-49.

de Castro, J. M., Bellisle, F., \& Dalix, A. M. (2000). Palatability and intake relationships in free-living humans. Measurement and characterization in the French. Physiology $\mathcal{E}$ Behavior, 68, 271-277.

Drewnowski, A. (2007). The real contribution of added sugars and fats to obesity. Epidemiologic Reviews, 29, 160-171.
Drewnowski, A., \& Bellisle, F. (2007). Is sweetness addictive? Nutrition Bulletin, 32(Suppl. 1), 52-60.

Eertmans, A., Baeyens, F., \& Van den Bergh, O. (2001). Food likes and their relative importance in human eating behavior. Review and preliminary suggestions for health promotion. Health Education Research, 16, 443-456.

Epstein, L. H., Truesdale, R., Wojcik, A., Paluch, R. A., \& Raynor, H. A. (2003). Effects of deprivation on hedonics and reinforcing value of food. Physiology \& Behavior, 78, 221-227.

Evans, A. H., Pavese, N., Lawrence, A. D., Tai, Y. F., Appel, S., Dover, M., et al. (2006). Compulsive drug use linked to sensitized ventral striatal dopamine transmission. Annals of Neurology, 59, 852-858.

Finlayson, G., King, N., \& Blundell, J. (2008). The role of implicit wanting in relation to explicit liking and wanting for food. Implications for appetite control. Appetite, 50, $120-127$.

Finlayson, G., King, N., \& Blundell, J. E. (2007a). Is it possible to dissociate "liking" and "wanting" for foods in humans? A novel experimental procedure. Physiology $\mathcal{E}$ Behavior, 90, 36-42.

Finlayson, G., King, N., \& Blundell, J. E. (2007b). Liking vs. wanting food. Importance for human appetite control and weight regulation. Neuroscience and Biobehavioral Reviews, 31, 987-1002.

Forestell, C., \& Mennella, J. (2007). Early determinants of fruit and vegetable acceptance. Pediatrics, $120,1247-1254$

Franken, I. H. A. (2003). Drug craving and addiction. Integrating psychological and neuropsychopharmacological approaches. Progress in Neuro-Psychopharmacology and Biological Psychiatry, 27, 563-579.

Ganchrow, J., Steiner, J., \& Daher, M. (1983). Neonatal facial expressions in response to different qualities and intensities of gustatory stimuli. Infant Behavior and Development, 6, 189-200.

Giesen, J. C. A. H. , Havermans, R. C., Douven, A., Tekelenburg, M., \& Jansen, A. (2010). Will work for snack food. The association of BMI and snack reinforcement. Obesity, $18,966-970$

Giesen, J. C. A. H. , Havermans, R. C., \& Jansen, A. (2010). Substituting snacks with strawberries and sudokus. Does restraint matter? Health Psychology, 29, 222-226.

Giesen, J. C. A. H. , Havermans, R. C., Nederkoorn, C., Strafaci, S., \& Jansen, A. (2009). Working harder to obtain more snack foods when wanting to eat less. Behaviour Research and Therapy, 47, 13-17.

Goldfield, G. S., \& Epstein, L. H. (2002). Can fruits and vegetables and activities substitute for snack foods? Health Psychology, 21, 299-303.

Gosnell, B. A. (2005). Sucrose intake enhances behavioral sensitization produced by cocaine. Brain Research, 1031, 194-201.

Gosnell, B. A., \& Levine, A. S. (2009). Reward systems and food intake. Role of opioids. International Journal of Obesity, 33(Suppl. 2), 54-58.

Havermans, R. C., Giesen, J. C. A. H. , Houben, K., \& Jansen, A. (2011). Weight, gender, and snack appeal. Eating Behaviors, 12, 126-130.

Havermans, R. C., Janssen, T., Giesen, J. C. A. H. , Roefs, A., \& Jansen, A. (2009). Food liking, food wanting, and sensory-specific satiety. Appetite, 52, 222-225.

Heatherton, T. F., Herman, C. P., Polivy, J., King, G. A., \& McGree, S. T. (1988). The (mis)measurement of restraint. An analysis of conceptual and psychometric issues. Journal of Abnormal Psychology, 97, 19-28.

Herman, C. P., \& Mack, D. (1975). Restrained and unrestrained eating. Journal of Personality, 43, 647-660.

Hobbs, M., Remington, B., \& Glautier, S. (2005). Dissociation of wanting and liking for alcohol in humans. A test of the incentive-sensitization theory. Psychopharmacology, 178, 493-499.

Jansen, A., \& Van den Hout, M. (1991). On being led into temptation. "Counterregulation" of dieters after smelling a "preload". Addictive Behaviors, 16, 247-253.

Jansen, A., Vanreyten, A., Balveren, T., van Roefs, A., Nederkoorn, C., \& Havermans, R. (2008). Negative affect and cue-induced overeating in non-eating disordered obesity. Appetite, 51, 556-562.

Jeffery, R. W., Drewnowski, A., Epstein, L. H., Stunkard, A. J., Wilson, G. T., Wing, R. R., et al. (2000). Long-term maintenance of weight loss. Current status. Health Psychology, 19, 5-16.

Jéquier, E. (2002). Pathways to obesity. International Journal of Obesity, 26(Suppl.), 1217.

Kelley, A. E., Bakshi, V. P., Haber, S. N., Steininger, T. L., Will, M. J., \& Zhang, M. (2002). Opioid modulation of taste hedonics within the ventral striatum. Physiology $\mathcal{E}$ Behavior, 76, 365-377.

Krieglmeyer, R., Deutsch, R., De Houwer, J., \& De Raedt, R. (2010). Being moved. Valence activates approach-avoidance behavior independently of evaluation and approach-avoidance intentions. Psychological Science, 21, 607-613.

Leddy, J. J., Epstein, L. H., Jaroni, J. L., Roemmich, J. N., Paluch, R. A., Goldfield, G. S., et al. (2004). The influence of methylphenidate on eating in obese men. Obesity Research, $12,224-232$.

Ledikwe, J. H., Rolls, B. J., Smiciklas-Wright, H., Mitchell, D. C., Ard, J. D., Champagne, C., et al. (2007). Reductions in dietary energy density are associated with weight loss in overweight and obese participants in the PREMIER trial. American Journal of Clinical Nutrition, 85, 1212-1221.

Lemmens, S. G. T., Schoffelen, P. F. M., Wouters, L., Born, J. M., Martens, M. J. I., Rutters, F., et al. (2009). Eating what you like induces a stronger decrease of "wanting" to eat. Physiology \& Behavior, 98, 318-325.

Levine, A. S., \& Billington, C. J. (2004). Opioids as agents of reward-related feeding. A consideration of the evidence. Physiology \& Behavior, 82, 57-61.

Leyton, M., Boileau, J., Benkelfat, C., Diksic, M., Bohen, G., \& Dagher, A. (2002) Amphetamine-induced increases in extracellular dopamine, drug wanting and novelty seeking. A PET $/\left[{ }^{11} \mathrm{C}\right]$ raclopride study in healthy men. Neuropsychopharmacology, 27, 1027-1035. 
Lowe, M. R., \& Butryn, M. L. (2007). Hedonic hunger. A new dimension of appetite? Physiology \& Behavior, 91, 432-439.

Lowe, M. R., \& Levine, A. S. (2005). Eating motives and the controversy over dieting. Eating less than needed versus less than wanted. Obesity Research, 13, 797-806.

Mela, D. J. (2006). Eating for pleasure or just wanting to eat? Reconsidering sensory hedonic responses as a driver of obesity. Appetite, 47, 10-17.

Mustonen, S., Hissa, I., Huotilainen, A., Miettinen, S.-M., \& Tuorila, H. (2007). Hedonic responses as predictors of food choice. Flexibility and self-prediction. Appetite, 49, 159-168.

Ostafin, B. D., Marlatt, G. A., \& Troop-Gordon, W. (2010). Testing the incentivesensitization theory with at-risk drinkers. Wanting, liking, and alcohol consumption. Psychology of Addictive Behaviors, 24, 157-162.

Ouwehand, C., \& de Ridder, D. T. D. (2008). Effects of temptation and weight on hedonics and motivation to eat in women. Obesity, 16, 1788-1793.

Ouwehand, C., \& Papies, E. K. (2010). Eat it or beat it. The differential effects of food temptations on overweight and normal-weight restrained eaters. Appetite, 55, 5660.

Papies, E., Stroebe, W., \& Aarts, H. (2008). Understanding dieting. A social cognitive analysis of hedonic processes in self-regulation. European Review of Social Psychology, 19, 339-383.

Peciña, S., \& Berridge, K. C. (2005). Hedonic hot spot in nucleus accumbens shell. Where do mu-opioids cause increased hedonic impact of sweetness? Journal of Neuroscience, 25, 11777-11786.

Peciña, S., Cagniard, B., Berridge, K. C., Aldridge, J. W., \& Zhuang, X. (2003). Hyperdopaminergic mutant mice have higher "wanting" but not "liking" for sweet rewards. Journal of Neuroscience, 23, 9395-9402.

Peciña, S., Smith, K. S., \& Berridge, K. C. (2006). Hedonic hot spots in the brain. Neuroscientist, 12, 500-511.

Pelchat, M. L., Johnson, A., Chan, R., Valdez, J., \& Ragland, J. D. (2004). Images of desire. Food-craving activation during fMRI. NeuroImage, 23, 1486-1493.

Robinson, T. E., \& Berridge, K. C. (1993). The neural basis of drug craving. An incentive sensitization theory of addiction. Brain Research and Review, 18, 247-291.

Robinson, T. E., \& Berridge, K. C. (2000). The psychology and neurobiology of addiction. An incentive sensitization view. Addiction, 95(Suppl. 2), 91-117.

Robinson, T. E., \& Berridge, K. C. (2003). Addiction. Annual Review of Psychology, 54, 25-53.

Rosenstein, D., \& Oster, H. (1988). Differential facial responses to four basic tastes in newborns. Child Development, 59, 1555-1568.

Rozin, P. (1996). Sociocultural influences on human food selection. In E. D. Capaldi (Ed.), Why we eat what we eat: The psychology of eating (pp. 233-263). Washington: American Psychological Association.

Saelens, B. E., \& Epstein, L. H. (1996). Reinforcing value of food in obese and non-obese women. Appetite, 27, 41-50.

Schotte, D. E., Cools, J., \& McNally, R. J. (1990). Film-induced negative affect triggers overeating in restrained eaters. Journal of Abnormal Psychology, 99, 317-320.

Siep, N., Roefs, A., Roebroeck, A., Havermans, R., Bonte, M. L., \& Jansen, A. (2009). Hunger is the best spice. An fMRI study of the effects of attention, hunger and calorie content on food reward processing in the amygdala and orbitofrontal cortex. Behavioural Brain Research, 198, 149-158.

Smith, K. S., \& Berridge, K. C. (2005). The ventral pallidum and hedonic reward. Neurochemical maps of sucrose "liking" and food intake. Journal of Neuroscience, $25,8637-8649$.

Soussignan, R., Schaal, B., Marlier, L., \& Jiang, T. (1997). Facial and autonomic responses to biological and artificial olfactory stimuli in human neonates. Re-examining early hedonic discrimination of odors. Physiology \& Behavior, 62, 745-758.
Steiner, J. E. (1974). Innate, discriminative human facial expressions to taste and smell stimulation. Annals of the New York Academy of Sciences, 237, 229-233.

Steiner, J. E., Glaser, D., Hawilo, M. E., \& Berridge, K. C. (2001). Comparative expression of hedonic impact. Affective reactions to taste by human infants and other primates. Neuroscience and Biobehavioral Reviews, 25, 53-74.

Stice, E., Spoor, S., Bohon, C., \& Small, D. M. (2008). Relation between obesity and blunted striatal response to food is moderated by TaqlA1 DRD2 gene. Science, 322 449-452.

Stice, E. Yokum, S., Blum, K., \& Bohon, C. (2010). Weight gain is associated with reduced striatal response to palatable food. Journal of Neuroscience, 30, 13105-13109.

Stice, E., Yokum, S., Bohon, C., Marti, N., \& Smolen, A. (2010). Reward circuitry responsivity to food predicts future increases in body mass. Moderating effects of DRD2 and DRD4. Neurolmage, 50, 1618-1625.

Strakowski, S. M., \& Sax, K. J. (1998). Progressive behavioral response to repeated damphetamine challenge. Further evidence for sensitization in humans. Biological Psychiatry, 44, 1171-1177.

Stroebe, W., Papies, E. K., \& Aarts, H. (2008). From homeostatic to hedonic theories of eating. Self-regulatory failure in food-rich environments. Applied Psychology: An International Review, 57, 172-193.

Swinburn, B. A., Sacks, G., Lo, S. K., Westerterp, K. R., Rush, E. C., Rosenbaum, M., et al (2009). Estimating the changes in energy flux that characterize the rise in obesity prevalence. American Journal of Clinical Nutrition, 89, 1723-1728.

Tibboel, H., De Houwer, J., Spruyt, A., Field, M., Kemps, E., \& Crombez, G. (2011). Testing the validity of implicit measures of wanting and liking. Journal of Behavior Therapy and Experimental Psychiatry, 42, 284-292.

Tindell, A. J., Berridge, K. C., Zhang. J., Peciña, S. \& Aldridge, J. W. (2005). Ventral pallidal neurons code incentive motivation. Amplification by mesolimbic sensitization and amphetamine. European Journal of Neuroscience, 22, 2617-2634.

Veenstra, E. M., \& de Jong, P. J. (2010). Restrained eaters show enhanced automatic approach tendencies towards food. Appetite, 55, 30-36.

Volkow, N. D., Wang, G.-J., Telang, F., Fowler, J. S., Thanos, P. K., Logan, J., et al. (2008). Low dopamine striatal D2 receptors are associated with prefrontal metabolism in obese subjects. Possible contributing factors. Neurolmage, 42, 1537-1543.

Wang, G. J., Volkow, N. D., Logan, J., Pappas, N. R., Wong, C. T., Zhu, W., et al. (2001) Brain dopamine and obesity. Lancet, 357, 354-357.

Westerterp, K. R., \& Speakman, J. R. (2008). Physical activity energy expenditure has not declined since the 1980s and matches energy expenditures of wild mammals. International Journal of Obesity, 32, 1256-1263.

Willner, P., James, D., \& Morgan, M. (2005). Excessive alcohol consumption and dependence on amphetamine are associated with parallel increases in subjective ratings of both "wanting" and "liking". Addiction, 100, 1487-1495.

Wyvell, C. L., \& Berridge, K. C. (2001). Incentive sensitization by previous amphetamine exposure. Increased cue triggered "wanting” for sucrose reward. Journal of Neuroscience, 21, 7831-7840.

Yeomans, M. R., Blundell, J. E., \& Leshem, M. (2007). Palatability. Response to nutritional need or need-free stimulation of appetite? British Journal of Nutrition, 92(Suppl. 1), 3-14.

Yeomans, M. R., \& Gray, R. W. (2002). Opioid peptides and the control of human ingestive behaviour. Neuroscience and Biobehavioral Reviews, 26, 713-728.

Young, P. T. (1959). The role of affective processes in learning and motivation. Psychological Review, 66, 104-125.

Zeinstra, G. G., Koelen, M., Colindres, D., Kok, F. J., \& de Graaf, C. (2009). Facial expressions in school-aged children are a good indicator of "dislikes", but not of "likes". Food Quality and Preference, 20, 620-624. 